\title{
Mixed Convection Flow of Powell-Eyring Nanofluid near a Stagnation Point along a Vertical Stretching Sheet
}

\author{
Nadhirah Abdul Halim ${ }^{1,+}$ (D) and Noor Fadiya Mohd Noor $2, *,+$ (D) \\ 1 Faculty of Computer and Mathematical Sciences, Universiti Teknologi MARA, Shah Alam 40450, \\ Selangor, Malaysia; nadhirahhalim@uitm.edu.my \\ 2 Institute of Mathematical Sciences, Faculty of Science, University of Malaya, Kuala Lumpur 50603, Malaysia \\ * Correspondence: drfadiya@um.edu.my; Tel.: +60-3-7967-4320 \\ + These authors contributed equally to this work.
}

Citation: Halim, N.A.; Noor, N.F.M

Mixed Convection Flow of

Powell-Eyring Nanofluid near a Stagnation Point along a Vertical

Stretching Sheet. Mathematics 2021, 9

364. https://doi.org/10.3390/math 9040364

Received: 30 September 2020

Accepted: 6 January 2021

Published: 11 February 2021

\begin{abstract}
A stagnation-point flow of a Powell-Eyring nanofluid along a vertical stretching surface is examined. The buoyancy force effect due to mixed convection is taken into consideration along with the Brownian motion and thermophoresis effect. The flow is investigated under active and passive controls of nanoparticles at the surface. The associating partial differential equations are converted into a set of nonlinear, ordinary differential equations using similarity conversions. Then, the equations are reduced to first-order differential equations before further being solved using the shooting method and $b v p 4 c$ function in MATLAB. All results are presented in graphical and tabular forms. The buoyancy parameter causes the skin friction coefficient to increase in opposing flows but to decrease in assisting flows. In the absence of buoyancy force, there is no difference in the magnitude of the skin friction coefficient between active and passive controls of the nanoparticles. Stagnation has a bigger influence under passive control in enhancing the heat transfer rate as compared to when the fluid is under active control. Assisting flows have better heat and mass transfer rates with a lower magnitude of skin friction coefficient as compared to opposing flows. In this case, the nanofluid parameters, the Brownian motion, and thermophoresis altogether reduce the overall heat transfer rates of the non-Newtonian nanofluid.
\end{abstract}

Keywords: stagnation point; Powell-Eyring nanofluid; zero mass flux; vertical stretching sheet; mixed convection

\section{Introduction}

Mixed convection flow occurs when effects from forced convection and natural convection mechanisms contribute significantly to heat transfer. According to Chen et al. [1], the buoyancy force that arises from the temperature difference will instigate a longitudinal pressure gradient. This phenomena will affect the flow area and the heat transfer rate from the surface. A stagnation flow in pure forced convection usually represents the rather symmetric flow in the vicinity of a stagnation point line. However, a mixed convection stagnation flow will no longer be symmetrical towards the stagnation line [2]. Earlier on, Merkin [3] discussed dual-solution phenomena that occur in mixed convection of a porous medium. By considering a simple time-dependent problem, they showed that the upper branch of solutions is stable whilst the lower branch is unstable. Ishak et al. [4] examined the mixed convection flow of an incompressible viscous fluid towards a stretching vertical surface near a stagnation-point. Their study shows that a dual solution exists for the opposing flow whilst a unique solution is available for the assisting flow. Later, they investigated the effects that stagnation mixed convection flow had when a constant magnetic field is applied normal to the vertical plate [5]. With applied suction and injection on the surface, their results show that the dual solution actually exists for both assisting and opposing flows. Suction as well as electromagnetic field increase the range of buoyancy for which the solution may exist. Bognar [6] decided to present a theoretical analysis on similarity 
solutions for an opposing flow in a power-law fluid over a flat surface. They gave an analytic estimation for the critical value that depends on the power-law exponent and proved the existence of the analytic solution. Hayat et al. [7] applied the homotopy analysis method (HAM) in their study on the influence of thermal radiation on the MHD stagnation point flow with mixed convection. Both thermal radiation and magnetic parameter are found to improve the heat transfer rate of the fluid in assisting flows as well as in opposing flows. Aman et al. [8] considered a boundary slip in the mixed convection stagnation-point flow on a vertical surface. In their study, velocity slip helps to improve the heat transfer rate while the thermal slip worsens it. Abbas et al. [9] discussed the stagnation point flow of a Maxwell fluid on a stretching vertical surface with mixed convection. They found that increasing the fluid relaxation time represented by the Deborah number will increase the heat transfer rate in opposing flow but will decrease it in assisting flow. Hayat et al. [10] studied the stagnation-point flow of Casson fluid with mixed convection under convective boundary conditions. Their result shows that the Biot number has a qualitatively similar effect towards velocity and temperature profiles. Tian et al. [11] carried out a numerical inspection on MHD convective stagnation point flow of a non-Newtonian nanofluid over a stretching surface using collocation spectral method (CSM). They found that heat transfer in the boundary layer is heavily influenced by concentration of the saturated nanoparticles.

Heat transfer has wide applications in numerous devices and systems in automotive, materials processing, power station engineering, and thermal management, to name a few. The heat transfer fluid plays a major role in the performance of these devices and systems. Since Choi [12] introduced nanofluid to the world 20 years ago; it has gained lots of interest among researchers as a new heat transfer fluid due to its ability to improve a fluid's thermal conductivity. Nowadays, there is a lot of literature on the mixed convection stagnation point flow of nanofluids. Some of them include work from Makinde et al. [13] that studied the influences buoyancy force and magnetic field had on stagnation point flow towards a convectively heated surface. Here, the buoyancy force helps to improve the heat transfer rate of the fluid. Pal and Mandal [14] researched the effects of thermal radiation, heat generation, and viscous dissipation past a mixed convection flow over a stretching/shrinking surface that carries a nanofluid. Hsiao [15] investigated the stagnation point flow of a nanofluid with electrical magnetohydrodynamic (EMHD) and slip boundary effects on a stretching surface. Abbasi et al. [16] analyzed the mixed convection flow of a Jeffrey nanofluid while taking into consideration the effects of thermal radiation and double stratifications. Their result shows that thermal radiation increases the fluid temperature, but thermal stratification lowers the temperature. Othman et al. [17] did a study that covers a stagnation point of a mixed convection flow saturated with a controlled nanoparticle concentration over an impermeable, vertically stretched/shrinked surface. Results show that increasing values of the mixed convection parameter will raise the values of the skin friction coefficient as well as both heat and mass transfer rates near the wall surface. Zaib et al. [18] did an analysis focusing on the dual-nature solution for the entropy generation along a Riga surface. In their study, the dual solutions are obtained only in opposing flow. Alizadeh et al. [19] examined the impact of radiation and electromagnetic field in a mixed convection stagnation-point flow surrounding a cylinder. It is concluded that the radiative system produces a higher Nusselt number and less thermal irreversibilities. Additionally, changes in Biot number allow the modification of the predicted value of Nusselt numbers. Jamaludin et al. [20] investigated another mixed convection problem near a stagnation-point flow over a vertically stretched/shrinked plate with suction, thermal radiation, and heat source/sink. Their results confirmed that dual solutions appear within a particular range of the mixed convection parameters whereby the boundary layer separation takes place in the opposing flow region. They have also performed an analysis to verify the stability of the upper and lower branches solutions. Recently, solar radiation effect with internal energy of thermal diffusion and thermal conductivity in MHD stagnation-point flow of Maxwell fluid were considered by Khan et al. [21] who concluded that radiation increases the rate of heat transfer. 
Among the abundance of non-Newtonian fluids available, the Powell-Eyring fluid holds some advantages over the others, especially in chemical engineering. This particular fluid model is derived from the kinetic theory of liquids. Furthermore, the model can properly exhibit Newtonian behavior at low and high shear rates. Hayat et al. [22] did a study on MHD nonlinear stretching flow of a Powell-Eyring nanofluid where a zero nanoparticle mass flux condition was applied at the sheet. Their results show that a higher magnetic parameter value lowers the rate of the heat transfer at the surface, but it increases the skin friction coefficient. It was also found that Brownian motion and thermophoresis parameters reacted differently on the concentration field. Meanwhile, Hussain et al. [23] considered the radiative peristaltic flow of Powell-Eyring nanofluid in an asymmetric channel for their study. They found that the nonlinear radiation in the flow field increases the pressure gradient magnitude and reduces fluid temperature. Ibrahim and Godisa [24] presented finite element solutions of a boundary-layer flow of Powell-Eyring nanofluid over a nonlinear stretching sheet in the presence of heat generation/absoprtion and chemical reaction. Ogunsye et al. [25] used the nanofluid viscosity and thermal conductivity models derived from experimental data to investigate the flow and heat transfer of a Powell-Eyring nanofluid. The computational results show that heat transfer rate increases with increment of temperature ratio parameter and thermal radiation. Khan et al. [26] explored the flow of MHD mixed convection of Eyring-Powell nanofluid over a tilted plane with an exponentially varying viscosity. Ogunseye and Sibanda [27] studied the entropy generation in a Powell-Eyring $\mathrm{Al}_{2} \mathrm{O}_{3}$-water nanofluid flow passing through a vertical channel subjected to a convective cooling. The result shows that the concentration of nanoparticles as well as the Brinkman number play important roles in reducing the entropy generation rate in that channel. In recent works, Alsaedi et al. [28] studied the influence of Bejan number and entropy rate on Eyring-Powell nanofluid flow over a stretchable surface, while Waqas et al. [29] presented a numerical analysis of a nonlinear radiating Eyring-Powell nanofluid flow while taking into consideration the effects of magnetic dipole energy as well as activation energy. Aziz et al. [30] did an entropy analysis for a Powell-Eyring hybrid nanofluid flow in which the model includes the effects of linear thermal radiation and viscous dissipation. One of their main results uncovered the superiority of the hybrid Powell-Eyring nanofluid as a thermal conductor as compared to the conventional nanofluids. It is also shown that the highest heat flux is produced using the smallest shape factor parameter.

In this paper, the analysis will be focused more on the comparative study of the PowellEyring nanofluid flow under active and passive controls of nanoparticles. The influence of other parameters towards the flow are also looked at in detail. The governing equations will be simplified using similarity transformation before being solved using a shooting technique and bop4c function in MATLAB. All results are presented in graphical and tabular forms.

\section{Problem Formulation}

Take into account a steady two-dimensional mixed convection stagnation point flow of an incompressible Powell-Eyring nanofluid towards a vertical stretching surface. The Cartesian coordinate system is chosen in such a way that the $x$-axis is along the vertical linearly stretching surface at $y=0$, and the fluid occupies the area $y>0$ (Figure 1). Near the surface, velocity is assumed to be $u_{w}(x)=c x$ with temperature $T=T_{w}(x)$. Depending on the fluid environment setting, the fluid concentration is assumed to be constant $C=C_{w}$ under active control surroundings, but it will depend on the temperature gradient when put under passive control of nanoparticles. Velocity of the free stream flow is defined as $u_{e}(x)=a x$ with ambient temperature and concentration of $T_{\infty}$ and $C_{\infty}$, respectively. 


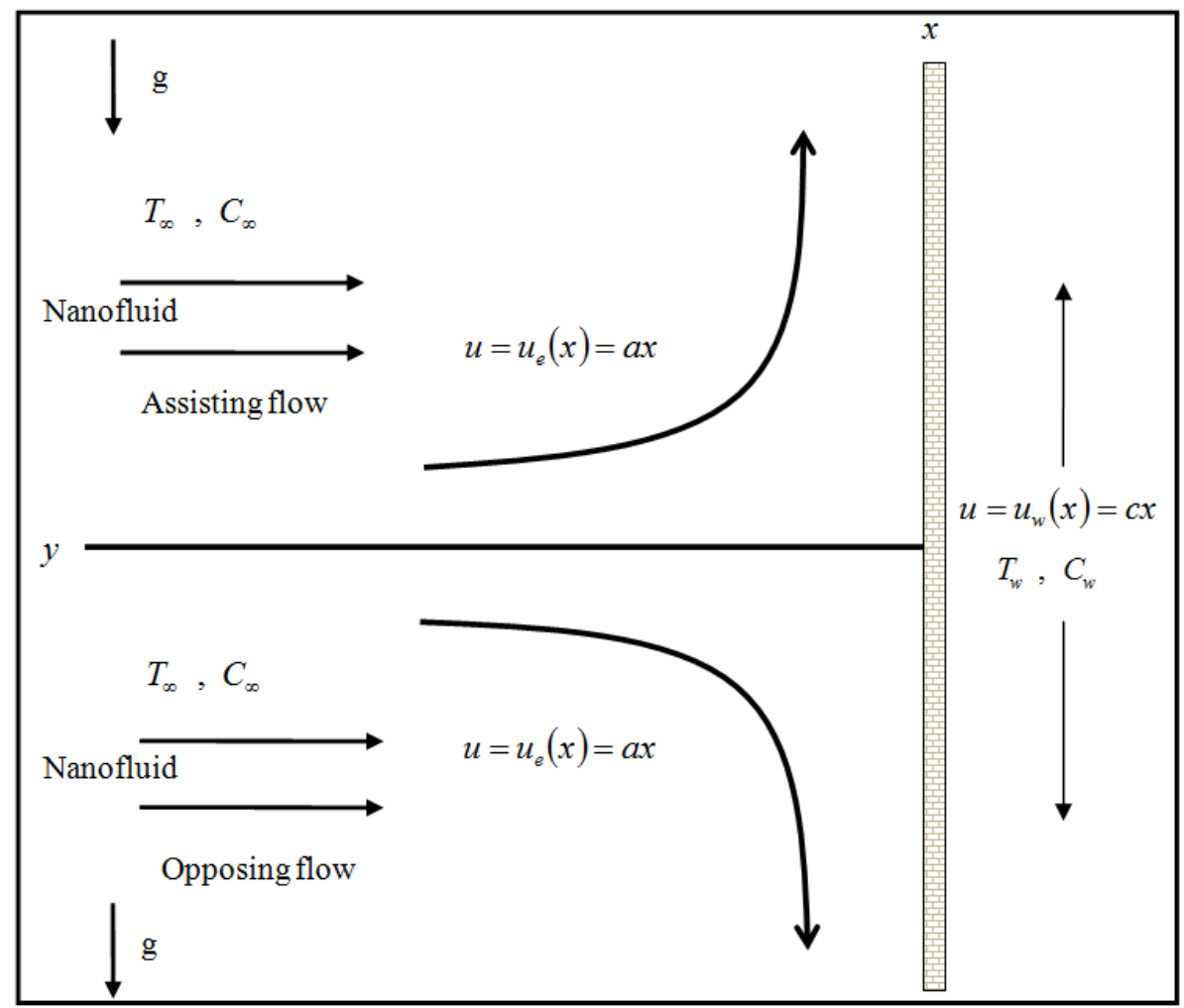

Figure 1. Geometry of the flow in Cartesian coordinates.

\subsection{The Continuity and Momentum Equations}

The governing equations are given by

$$
\begin{aligned}
& \frac{\partial u}{\partial x}+\frac{\partial u}{\partial y}=0, \\
& \begin{aligned}
u \frac{\partial u}{\partial x}+v \frac{\partial u}{\partial y}=u_{e} \frac{d u_{e}}{d x}+\left(v+\frac{1}{\rho \beta c_{*}}\right) \frac{\partial^{2} u}{\partial y^{2}}-\frac{1}{2 \rho \beta c_{*}^{3}}\left(\frac{\partial u}{\partial y}\right)^{2} \frac{\partial^{2} u}{\partial y^{2}} \\
+g\left[\beta_{T}\left(T-T_{\infty}\right)+\beta_{C}\left(C-C_{\infty}\right)\right]
\end{aligned}
\end{aligned}
$$

where $u$ and $v$ are the velocity components along $x$ - and $y$-axes, respectively. The term $u_{e} \frac{d u_{e}}{d x}$ represents the stagnation flow as it signifies the fluid flow normally (at 90 degrees) towards the vertical plate surface at free stream velocity [15]. In the momentum equation for Powell-Eyring fluid [31], $v=\mu / \rho$ is the kinematic viscosity, $\rho$ is the fluid density, and $\beta$ and $c_{*}$ are the fluid parameters. The mixed convection flow produces some buoyancy forces that change the flow field and heat and mass transfer rates from the surface. This is described in the last term of the momentum equation at which $g$ is the acceleration due to gravity, $\beta_{T}$ is the thermal expansion coefficient, $\beta_{C}$ is the nanoparticle volumetric coefficient, and $T$ and $C$ are the fluid temperature and concentration. The boundary conditions are

$$
\begin{array}{llrl}
u=u_{w}(x)=c x, & v=0 & & \text { at } \quad y=0 \\
u=u_{e}(x, t)=a x & & \text { as } & y \rightarrow \infty
\end{array}
$$

Here, $a$ and $c$ are positive constants. Similarity transformations are used by applying the following non-dimensional variables: 


$$
\begin{aligned}
& \eta=\sqrt{\frac{c}{v}} y, \quad \psi=\sqrt{c v} x f(\eta), \quad \quad \theta(\eta)=\frac{T-T_{\infty}}{T_{w}-T_{\infty}}, \\
& \phi(\eta)=\frac{C-C_{\infty}}{C_{\infty}}, \quad \text { for passive control of } \phi, \\
& \phi(\eta)=\frac{C-C_{\infty}}{C_{w}-C_{\infty}}, \quad \text { for active control of } \phi .
\end{aligned}
$$

where $\eta$ is the similarity variable, and $\psi$ is the stream function that satisfies (1) and

$$
u=\frac{\partial \psi}{\partial y}=c f^{\prime}(\eta) \quad \text { and } \quad v=-\frac{\partial \psi}{\partial x}=-\sqrt{c v} f(\eta) .
$$

By substituting (4) and (5) into the governing Equations (1) and (2), we have

$$
(1+\epsilon) f^{\prime \prime \prime}-\left(f^{\prime}\right)^{2}+f f^{\prime \prime \prime}+r^{2}-\epsilon \delta\left(f^{\prime \prime}\right)^{2} f^{\prime \prime \prime}+\gamma[\theta+N \phi]
$$

where primes denote the differentiation with respect to $\eta$. Here, $r=a / c$ is the stagnation parameter, $\epsilon=\frac{1}{\mu \beta c_{*}}$ and $\delta=\frac{c^{3} x^{2}}{2 c_{*}^{2} v}$ are the fluid parameters, $\gamma=\frac{g \beta_{T}\left(T-T_{\infty}\right) x^{3} / v^{2}}{\left(u_{w}(x) x / v\right)^{2}}$ is the buoyancy parameter, and $N=\frac{\beta_{C}\left(C-C_{\infty}\right)}{\beta_{T}\left(T-T_{\infty}\right)}$ is the buoyancy force ratio. The boundary condition (3) then becomes

$$
\begin{aligned}
& f(0)=0, \quad f^{\prime}(0)=1, \quad \text { at } \quad \eta=0 \\
& f^{\prime}(\infty)=r, \quad \text { as } \quad \eta \rightarrow \infty
\end{aligned}
$$

\subsection{The Energy and Mass Transport Equations}

The nanofluid energy and mass transport equations according to [32] are given by

$$
\begin{aligned}
& u \frac{\partial T}{\partial x}+v \frac{\partial T}{\partial y}=\kappa \frac{\partial^{2} T}{\partial y^{2}}+\tau D_{B} \frac{\partial C}{\partial y} \frac{\partial T}{\partial y}+\tau \frac{D_{T}}{T_{\infty}}\left(\frac{\partial T}{\partial y}\right)^{2} \\
& u \frac{\partial C}{\partial x}+v \frac{\partial C}{\partial y}=D_{B} \frac{\partial^{2} C}{\partial y^{2}}+\frac{D_{T}}{T_{\infty}} \frac{\partial^{2} T}{\partial y^{2}} .
\end{aligned}
$$

where $T$ and $C$ are the fluid temperature and concentration, $\kappa$ is the thermal diffusivity, $\tau$ is the effective heat capacity ratio of the nanoparticle and the fluid, $D_{B}$ is the Brownian diffusion coefficient, and $D_{T}$ is the thermophoretic diffusion coefficient. The appropriate boundary conditions are given as

$$
\begin{aligned}
& \text { At } y=0 \text { : } \\
& T=T_{w}(x), \\
& \begin{cases}D_{B} \frac{\partial C}{\partial y}+\frac{D_{T}}{T_{\infty}} \frac{\partial T}{\partial y}=0, & \text { for passive control of } \phi \\
C=C_{w}(x), & \text { for active control of } \phi\end{cases}
\end{aligned}
$$

As $y \rightarrow \infty$ :

$$
T=T_{\infty}, \quad C=C_{\infty}
$$

In a steady boundary layer flow, the temperature near the wall will be equal to the wall temperature, $T_{w}$, and as the flow moves further away from the wall, it will be equal to the ambient temperature, $T_{\infty}$. Under passive control of nanoparticles, it is assumed that the nanoparticle volume fraction is controlled passively on the surface via a temperature gradient. This is contrary to when the fluid is under active control of nanoparticles, where it is assumed to be constant at the surface. However, the nanoparticle volume concentration 
will reach a uniform value $C_{\infty}$ under both conditions as the flow moves further away. Applying the similarity transformation, the resulting equations will be

$$
\begin{aligned}
& \theta^{\prime \prime}+\operatorname{Pr}\left[f \theta^{\prime}+N b \theta^{\prime} \phi^{\prime}+N t\left(\theta^{\prime}\right)^{2}\right]=0 \\
& \phi^{\prime \prime}+L e \operatorname{Pr} f \phi^{\prime}+\frac{N t}{N b} \theta^{\prime \prime}=0
\end{aligned}
$$

with $\operatorname{Pr}=v / \kappa$ as the Prandtl number, $\mathrm{Nb}$ is the Brownian motion parameter where $N b=\frac{\tau D_{B} C_{\infty}}{v}$ (for passive control of $\phi$ ) and $N b=\frac{\tau D_{B}\left(C_{w}-C_{\infty}\right)}{v}$ (for active control of $\phi$ ), $N t=\frac{\tau D_{T}\left(T_{w}-T_{\infty}\right)}{v T_{\infty}}$ is the thermophoresis parameter, and $L e=\kappa / D_{B}$ is the Lewis number. The boundary conditions (10) will then become

$$
\text { At } \eta=0 \text { : }
$$

$$
\begin{aligned}
& \theta(0)=1, \\
& \begin{cases}N b \phi^{\prime}(0)+N t \theta^{\prime}(0)=0, & \text { for passive control of } \phi, \\
\phi(0)=1, & \text { for active control of } \phi,\end{cases}
\end{aligned}
$$

As $\eta \rightarrow \infty$ :

$$
\theta(\infty)=0, \quad \phi(\infty)=0,
$$

\subsection{Skin Friction Coefficient, Heat, and Mass Transfer Rate}

The physical quantities of practical interest are the local skin friction coefficient $C f_{x}$, the heat transfer rate or the local Nusselt number $N u_{x}$, and the mass transfer rate also known as local Sherwood number $S h_{x}$, which are defined as

$$
C f_{x}=\frac{\tau_{w}}{\rho u_{w}^{2}(x)}, \quad \quad N u_{x}=\frac{q_{w} x}{\alpha\left(T_{w}-T_{\infty}\right)}, \quad S h_{x}=-\frac{q_{m} x}{D_{B}\left(C_{w}-C_{\infty}\right)} .
$$

(for active control of $\phi$ )

Here, the surface shear stress $\tau_{w}$ [26], surface heat flux $q_{w}$, and the surface mass flux $q_{m}$ are given as follows

$$
\begin{aligned}
& \tau_{w}=\left[\left(v+\frac{1}{\rho \beta c_{*}}\right) \frac{\partial u}{\partial y}-\frac{1}{6 \beta c_{*}^{3}}\left(\frac{\partial u}{\partial y}\right)^{3}\right]_{y=0}, \\
& q_{w}=-\alpha\left(\frac{\partial T}{\partial y}\right)_{y=0}, \quad q_{m}=-D_{B}\left(\frac{\partial C}{\partial y}\right)_{y=0} .
\end{aligned}
$$

Equation (14) can then be simplified into the dimensionless form below:

$$
\begin{aligned}
& C f_{x} \operatorname{Re}_{x}^{1 / 2}=(1+\epsilon) f^{\prime \prime}(0)-\frac{\epsilon \delta}{3}\left(f^{\prime \prime}(0)\right)^{3}, \\
& N u_{x} R e_{x}^{-1 / 2}=-\theta^{\prime}(0), \\
& S h_{x} R e_{x}^{-1 / 2}=-\phi^{\prime}(0) .
\end{aligned}
$$

where $R e_{x}=U_{w} x / v$ stands for local Reynolds number. The local Sherwood number for passive control will follow the local Nusselt number accordingly with the boundary condition (10).

$$
S h_{x} R e_{x}^{-1 / 2}=\frac{N t}{N b} \theta^{\prime}(0)
$$

\section{Method of Solution}

The bop $4 c$ function in MATLAB was utilized in solving the problem. First, the governing nonlinear ordinary differential equations (ODEs) (Equations (6), (11) and (12)) 
with the boundary conditions (Equations (7) and (13)) are rewritten as a system of seven first-order ODEs:

$$
\begin{aligned}
& \chi_{1}^{\prime}=\chi_{2}, \\
& \chi_{2}^{\prime}=\chi_{3}, \\
& \chi_{3}^{\prime}=\frac{\left(\chi_{2}\right)^{2}-\chi_{1} \chi_{3}-r^{2}-\gamma\left[x_{4}+N \chi_{6}\right]}{1+\epsilon-\epsilon \delta\left(\chi_{3}\right)^{2}} \\
& \chi_{4}^{\prime}=\chi_{5}, \\
& \chi_{5}^{\prime}=-\operatorname{Pr}\left(\chi_{1} \chi_{5}+N b \chi_{5} \chi_{7}+N t\left(\chi_{5}\right)^{2},\right. \\
& \chi_{6}^{\prime}=\chi_{7}, \\
& \chi_{7}^{\prime}=-L e \operatorname{Pr} \chi_{1} \chi_{7}-\frac{N t}{N b} \chi_{5}^{\prime},
\end{aligned}
$$

with the boundary conditions

$$
\begin{aligned}
& \chi_{1}(0)=0, \quad \chi_{2}(0)=1, \quad \chi_{4}(0)=1 \\
& \begin{cases}N b \chi_{7}(0)+N t \chi_{5}(0)=0, & \text { for passive control of } \phi . \\
\chi_{6}(0)=1, & \text { for active control of } \phi\end{cases} \\
& \chi_{2}(\infty)=r, \quad \chi_{4}(\infty)=0, \quad \chi_{6}(\infty)=0
\end{aligned}
$$

where

$$
\begin{array}{ll}
\chi_{1}=f, & \chi_{2}=\chi_{1}^{\prime}=f^{\prime}, \quad \chi_{3}=\chi_{2}^{\prime}=f^{\prime \prime}, \\
\chi_{4}=\theta, & \chi_{5}=\chi_{4}^{\prime}=\theta^{\prime}, \\
\chi_{6}=\phi, & \chi_{7}=\chi_{6}^{\prime}=\phi^{\prime} .
\end{array}
$$

For calculation purposes, $\eta \rightarrow \infty$ in this problem is set to $\eta_{\infty}=10$, and the numerical solutions are evaluated at 100 equally spaced points with suitable initial guesses. The relative tolerance is set to $1 \times 10^{-12}$. To ensure the accuracy of our calculation and method of choice, results are compared with published results of others. Table 1 lists the compared values of $-\theta^{\prime}(0)$ for assorted values of the thermophorosis parameter $N t$. From the table, it is evident that the results are in good agreement with each other, thus validating the accuracy of the current results.

Table 1. Comparison table for values of Nusselt number, $N u$ for variation of thermophoresis parameter $N t$, when $r=\epsilon=\delta=\gamma=N=0, \operatorname{Pr}=3.97, N b=0.1$, and $L e=10 / \operatorname{Pr}$.

\begin{tabular}{ccc}
\hline \multirow{2}{*}{$\boldsymbol{N} t$} & Ishfaq et al. [33] & Current Study \\
\cline { 2 - 3 } & $\boldsymbol{R K} 4$ & $\boldsymbol{b v p 4 c}$ \\
\hline 0.1 & 1.2764 & 1.27637 \\
\hline 0.2 & 1.1836 & 1.18362 \\
\hline 0.3 & 1.0957 & 1.09571 \\
\hline 0.4 & 1.0131 & 1.01309 \\
\hline 0.5 & 0.9361 & 0.93607 \\
\hline
\end{tabular}

\section{Discussion}

This section discusses the impact that parameters $r, \epsilon, \delta, \gamma, N, N t, N b, L e$, and $P r$ have on the fluid flow characteristics, specifically the velocity, temperature, and concentration. Values of a particular parameter are varied, and the results are presented in graphical form in Figures 2-10. The physical properties of interest, which are the skin friction coefficient $f^{\prime \prime}(0)$, the heat transfer rate $-\theta^{\prime}(0)$ or Nusselt number $N u$, and the mass transfer rate 
$-\phi^{\prime}(0)$ or Sherwood number $S h$, are calculated numerically and recorded in tabular form (Tables 2 and 3). The parameter values used throughout this section are $r=0.2, \epsilon=$ $0.3, \delta=0.1, \gamma=1, N=N t=N b=0.5, L e=1$, andPr $=5$, unless stated otherwise.

Table 2. Values of $f^{\prime \prime}(0),-\theta^{\prime}(0)$, and $-\phi^{\prime}(0)$ for parameters $r, \epsilon, \delta, \gamma$ and $N$ under active and passive controls.

\begin{tabular}{ccccccccccc}
\hline & & & & \multicolumn{2}{c}{$f^{\prime \prime}(\mathbf{0})$} & \multicolumn{2}{c}{$-\boldsymbol{\theta}^{\prime}(\mathbf{0})$} & \multicolumn{2}{c}{$-\boldsymbol{\phi}^{\prime}(\mathbf{0})$} \\
\cline { 5 - 10 } & $\boldsymbol{N}$ & $\delta$ & $\gamma$ & $\boldsymbol{N}$ & Active & Passive & Active & Passive & Active & Passive \\
\hline 0.2 & 0.3 & 0.1 & 1 & 0.5 & -0.3071 & -0.5445 & 0.1620 & 1.2594 & 1.9210 & -1.2594 \\
0.5 & & & & & -0.1121 & -0.3418 & 0.1628 & 1.3079 & 1.9985 & -1.3079 \\
1.0 & & & & & 0.4303 & 0.2151 & 0.1673 & 1.4104 & 2.1538 & -1.4104 \\
1.2 & & & & & 0.7128 & 0.5023 & 0.1698 & 1.4540 & 2.2185 & -1.4540 \\
0.2 & 0 & & & & -0.3009 & -0.5904 & 0.1623 & 1.2478 & 1.9108 & -1.2478 \\
& 0.1 & & & & -0.3041 & -0.5736 & 0.1622 & 1.2520 & 1.9144 & -1.2520 \\
& 0.3 & & & & -0.3071 & -0.5445 & 0.1620 & 1.2594 & 1.9210 & -1.2594 \\
& 0.5 & & & & -0.3074 & -0.5198 & 0.1618 & 1.2656 & 1.9269 & -1.2656 \\
& 0.7 & & & & -0.3062 & -0.4985 & 0.1617 & 1.2710 & 1.9321 & -1.2710 \\
& 0.3 & 0 & & & -0.3073 & -0.5438 & 0.1620 & 1.2595 & 1.9211 & -1.2595 \\
& 0.1 & & & -0.3071 & -0.5445 & 0.1620 & 1.2594 & 1.9210 & -1.2594 \\
& 0.3 & & & -0.3068 & -0.5457 & 0.1620 & 1.2591 & 1.9209 & -1.2591 \\
& 0.5 & & & -0.3065 & -0.5469 & 0.1620 & 1.2589 & 1.9208 & -1.2589 \\
& 0.7 & & & -0.3063 & -0.5482 & 0.1620 & 1.2586 & 1.9207 & -1.2586 \\
& 0.1 & -1 & & -1.4386 & -1.1039 & 0.1479 & 1.1653 & 1.5966 & -1.1653 \\
& & -0.5 & & -1.0936 & -0.9507 & 0.1524 & 1.1939 & 1.7275 & -1.1939 \\
& & 0 & & -0.8081 & -0.8081 & 0.1561 & 1.2184 & 1.8077 & -1.2184 \\
& & 0.5 & & -0.5493 & -0.6733 & 0.1592 & 1.2399 & 1.8695 & -1.2399 \\
& & 1 & & -0.3071 & -0.5445 & 0.1620 & 1.2594 & 1.9210 & -1.2594 \\
& & 1 & 0.0 & -0.4274 & -0.5383 & 0.1608 & 1.2560 & 1.8975 & -1.2560 \\
& & & 0.5 & -0.3071 & -0.5445 & 0.1620 & 1.2594 & 1.9210 & -1.2594 \\
& & 1 & -0.1899 & -0.5513 & 0.1631 & 1.2625 & 1.9429 & -1.2625 \\
& & & 2 & 0.0371 & -0.5666 & 0.1652 & 1.2684 & 1.9829 & -1.2684 \\
\hline & & & & & & & & & \\
& & & & & & & &
\end{tabular}

Table 3. Values of $f^{\prime \prime}(0),-\theta^{\prime}(0)$, and $-\phi^{\prime}(0)$ for parameters $N t, N b$, Le, and $P r$ under active and passive controls.

\begin{tabular}{cccccccccc}
\hline \multirow{2}{*}{$\boldsymbol{N} t$} & \multirow{2}{*}{$\boldsymbol{N}$} & \multirow{2}{*}{$\boldsymbol{L}$} & \multirow{2}{*}{$\boldsymbol{P r}$} & \multicolumn{2}{c}{$f^{\prime \prime}(\mathbf{0})$} & \multicolumn{2}{c}{$-\boldsymbol{\theta}^{\prime}(\mathbf{0})$} & \multicolumn{2}{c}{$-\boldsymbol{\phi}^{\prime}(\mathbf{0})$} \\
\cline { 5 - 9 } & & & & Active & Passive & Active & Passive & Active & Passive \\
\hline 0.1 & 0.5 & 1 & 5 & -0.3700 & -0.5772 & 0.3120 & 1.5658 & 1.7157 & -0.3132 \\
0.3 & & & & -0.3364 & -0.5615 & 0.2212 & 1.4090 & 1.8154 & -0.8454 \\
0.5 & & & & -0.3071 & -0.5445 & 0.1620 & 1.2594 & 1.9210 & -1.2594 \\
0.7 & & & & -0.2815 & -0.5263 & 0.1225 & 1.1202 & 2.0193 & -1.5683 \\
0.5 & 0.1 & & & -0.2593 & -0.5750 & 0.5876 & 1.2712 & 1.4680 & -6.3558 \\
& 0.3 & & & -0.3156 & -0.5489 & 0.3172 & 1.2615 & 1.9149 & -2.1025 \\
& 0.5 & & & -0.3071 & -0.5445 & 0.1620 & 1.2594 & 1.9210 & -1.2594 \\
& 0.7 & & & -0.2931 & -0.5426 & 0.0785 & 1.2584 & 1.8860 & -0.8989 \\
& 0.5 & 1 & & -0.3071 & -0.5445 & 0.1620 & 1.2594 & 1.9210 & -1.2594 \\
& 2 & & -0.3449 & -0.5255 & 0.1135 & 1.1013 & 2.7166 & -1.1013 \\
& & & -0.3653 & -0.5162 & 0.0963 & 1.0159 & 3.3040 & -1.0159 \\
& & & -0.3788 & -0.5107 & 0.0873 & 0.9614 & 3.7925 & -0.9614 \\
& 4 & & -0.1451 & -0.4212 & 0.4777 & 0.6640 & 0.5283 & -0.6640 \\
& 1 & 1 & -0.2693 & -0.5142 & 0.3335 & 1.0731 & 1.3429 & -1.0731 \\
& & 3 & -0.3071 & -0.5445 & 0.1620 & 1.2594 & 1.9210 & -1.2594 \\
& & 5 & -0.3258 & -0.5567 & 0.0697 & 1.3396 & 2.3250 & -1.3396 \\
\hline
\end{tabular}




\subsection{Dimensionless Velocity, Temperature, and Concentration Fields}

Figures 2 and 3 display the fluid profiles when stagnation parameter $r$ and fluid parameter $\epsilon$ are varied. Both parameters seem to bring out the same outcome from the fluid flow. The fluid velocity increases when $r$ and $\epsilon$ increase. The fluid velocity under active control is higher than the fluid velocity under passive control, but both eventually converge to a uniform velocity as the fluid moves away from the surface. As the velocity increases, both fluid temperature and concentration decrease. Heat is being dispersed quicker to the surroundings, and particles are being spread out farther with the fluid flow. In Figure 4, the effect of another fluid parameter $\delta$ is shown. Compared to fluid parameter $\epsilon$, fluid parameter $\delta$ does not seem to make significant impact towards the fluid profiles. Minimal changes can be seen in velocity where the velocity seems to be decreasing with increasing values of $\delta$, while changes in temperature and concentration are not visible.

$$
\epsilon=0.3, \delta=0.1, \gamma=\operatorname{Le}=1, \mathrm{~N}=\mathrm{Nb}=\mathrm{Nt}=0.5, \mathrm{Pr}=5
$$

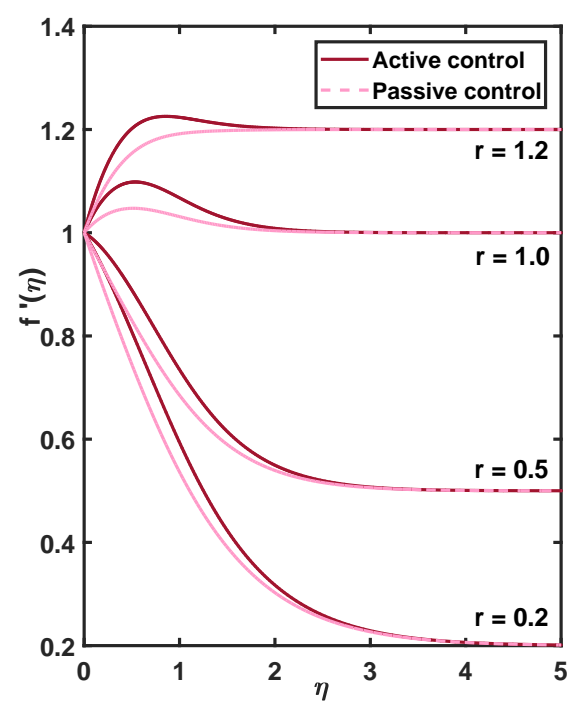

(a)

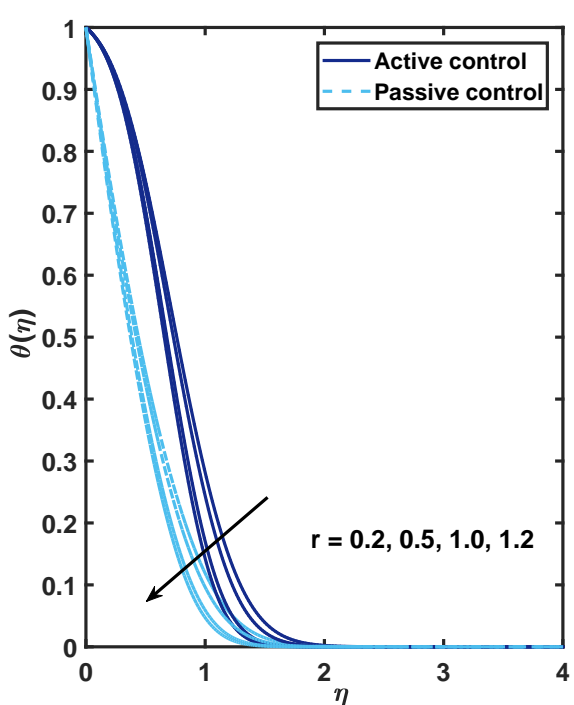

(b)

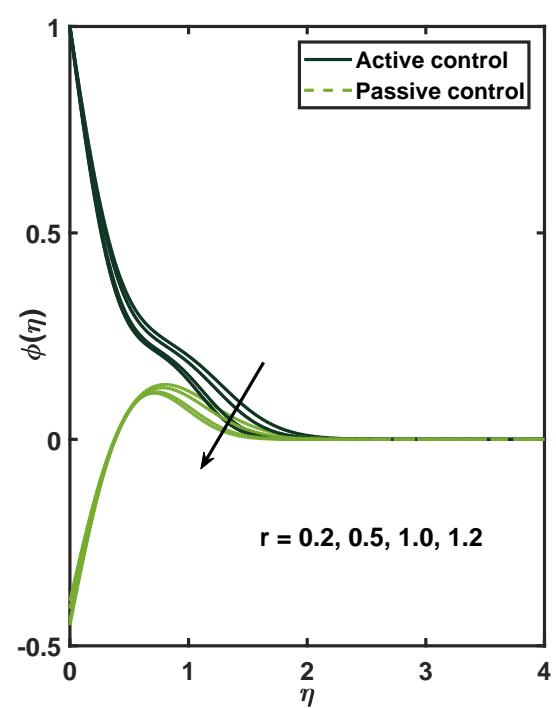

(c)

Figure 2. Impact of stagnation parameter $r$ on (a) velocity, (b) temperature, and (c) nanoparticle volume fraction profiles.

$$
r=0.2, \delta=0.1, \gamma=L e=1, N=N b=N t=0.5, \operatorname{Pr}=5
$$

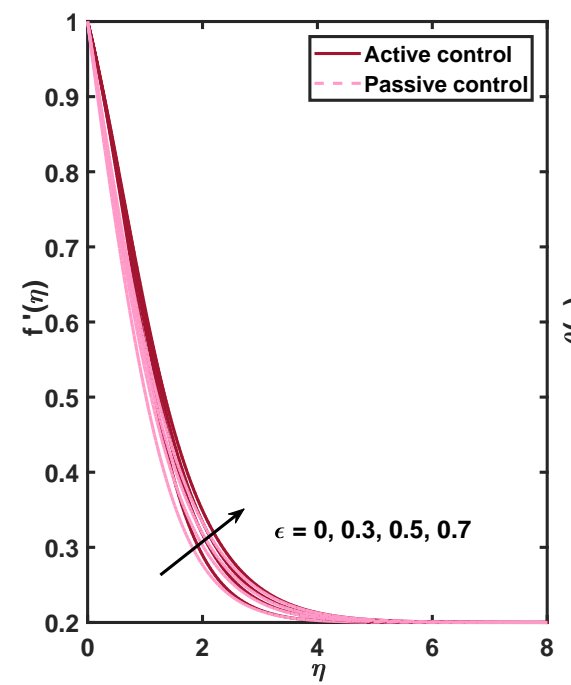

(a)

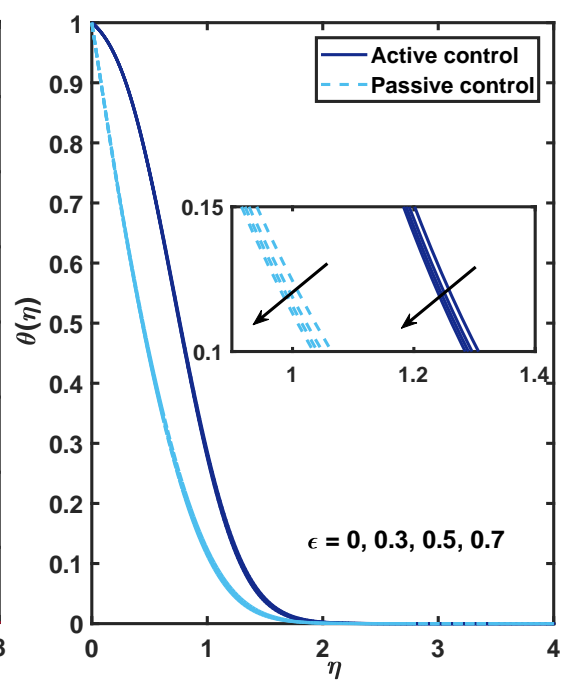

(b)

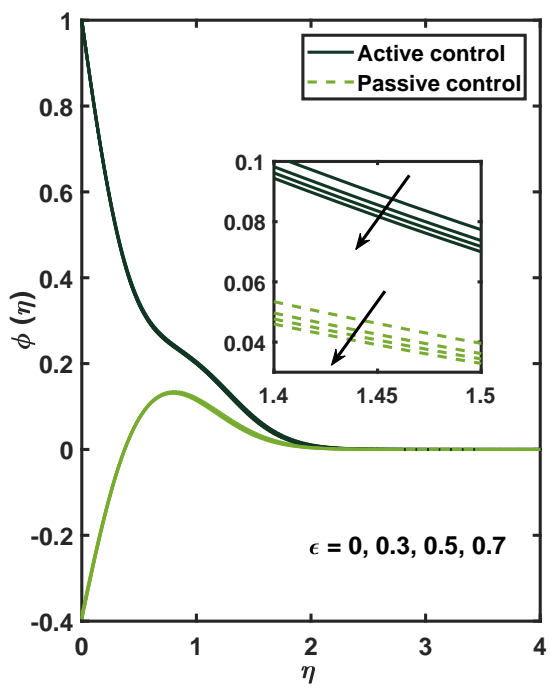

(c)

Figure 3. Impact of fluid parameter $\epsilon$ on (a) velocity, (b) temperature, and (c) nanoparticle volume fraction profiles. 
$\mathrm{r}=0.2, \epsilon=0.3, \gamma=\mathrm{Le}=1, \mathrm{~N}=\mathrm{Nb}=\mathrm{Nt}=0.5, \mathrm{Pr}=5$

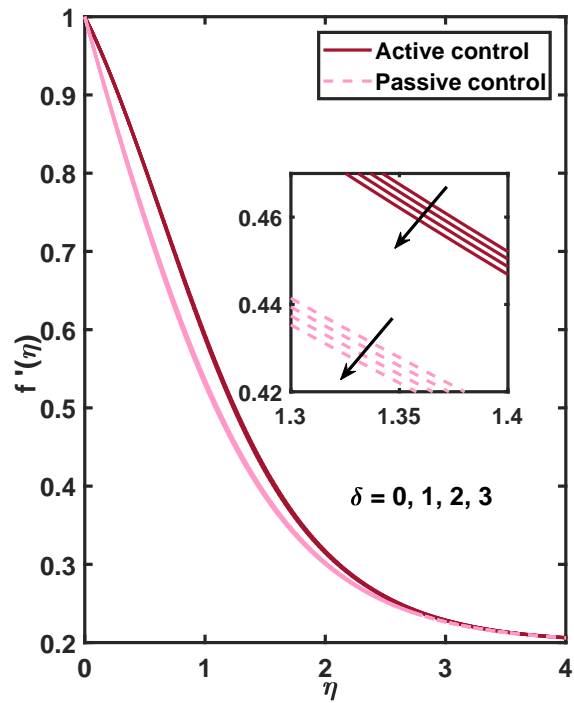

(a)

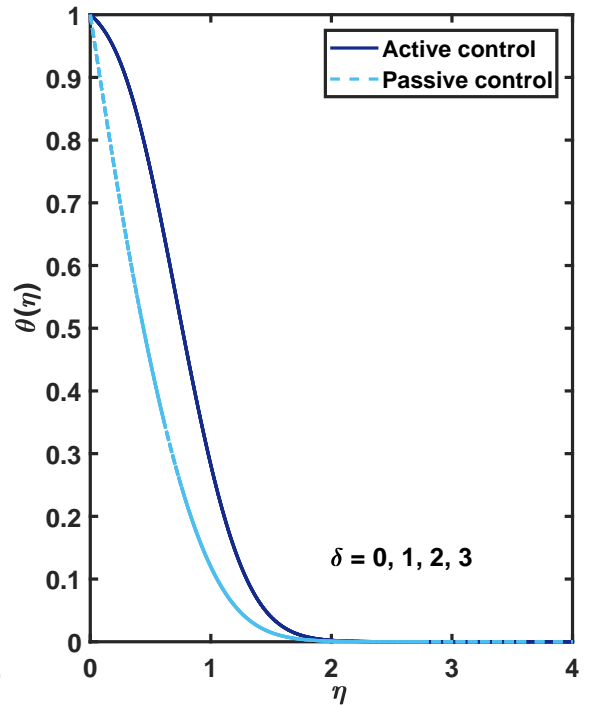

(b)

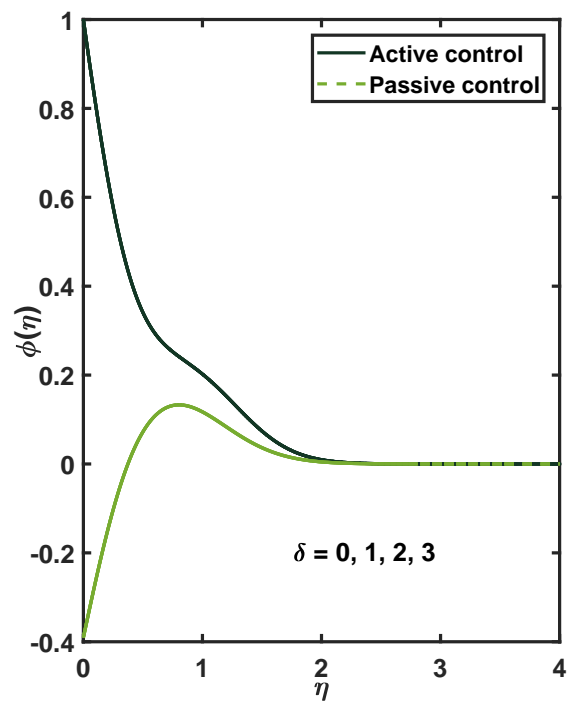

(c)

Figure 4. Impact of fluid parameter $\delta$ on (a) velocity, (b) temperature, and (c) nanoparticle volume fraction profiles.

Influences of the mixed convection parameter $\gamma$ and buoyancy ratio parameter $N$ are presented in Figures 5 and 6. The outcome is similar to those of varied $r$ and $\epsilon$. Fluid velocity increases, while temperature and concentration decrease when the value of parameters $\gamma$ and $N$ increase. Here, $\gamma>0$ represents assisting flow, $\gamma<0$ represents opposing flow, and $\gamma=0$ represents the flow when no buoyancy force is present. In assisting flow, fluid velocity is higher in active control than velocity in passive control. The opposite is true for the opposing flow. Relatively, the mixed convection parameter or the buoyancy parameter $\gamma$ leaves a bigger impact towards the flow profile than $N$.

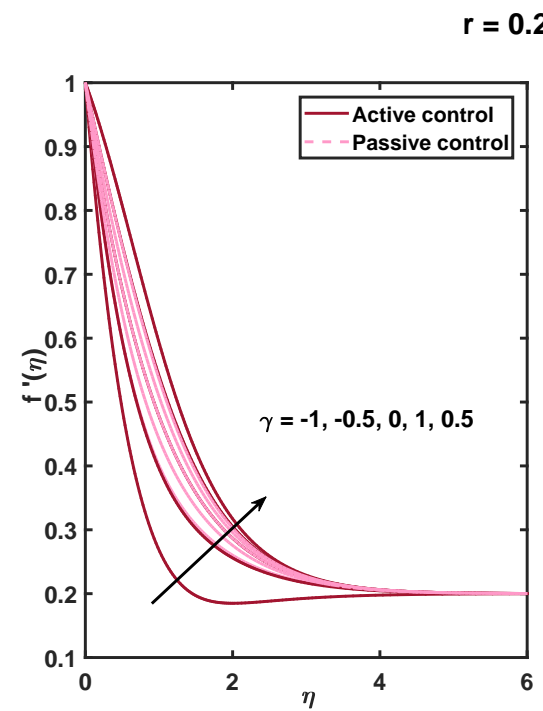

(a)

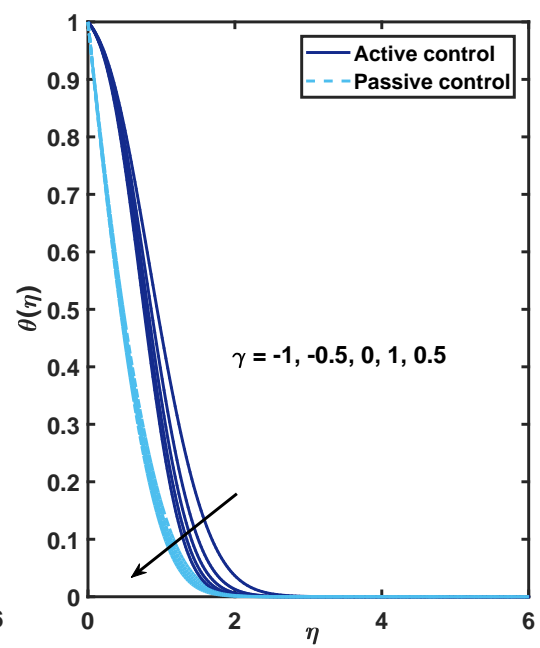

(b)

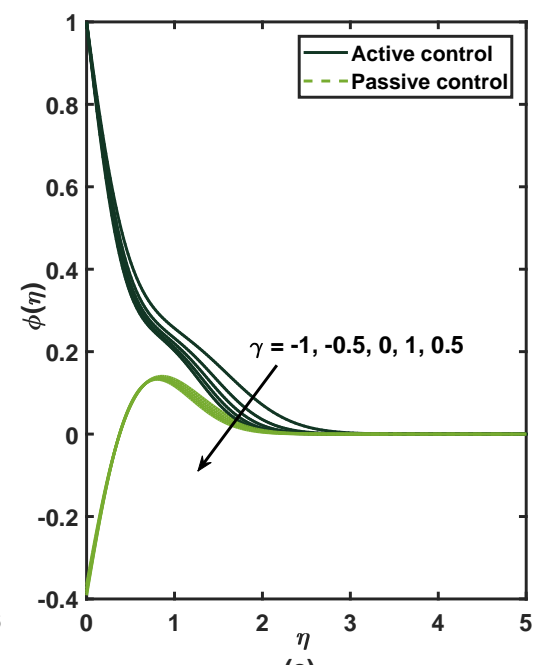

(c)

Figure 5. Impact of mixed convection parameter $\gamma$ on (a) velocity, (b) temperature, and (c) nanoparticle volume fraction profiles. 
$r=0.2, \epsilon=0.3, \delta=0.1, \gamma=\mathrm{Le}=1, \mathrm{Nb}=\mathrm{Nt}=0.5, \mathrm{Pr}=5$

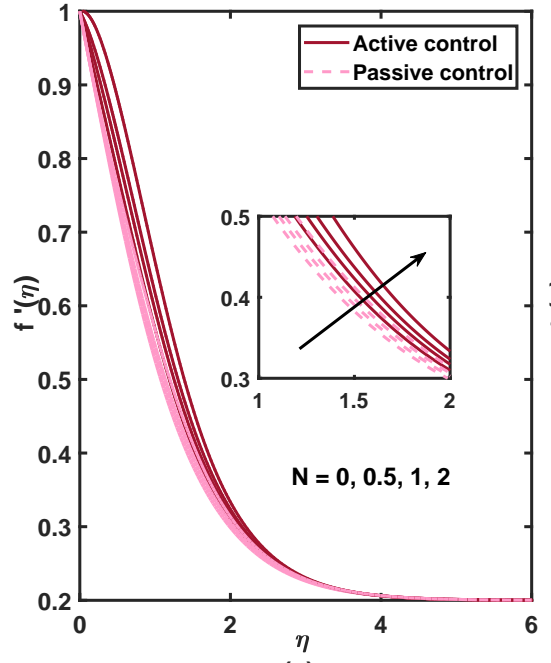

(a)

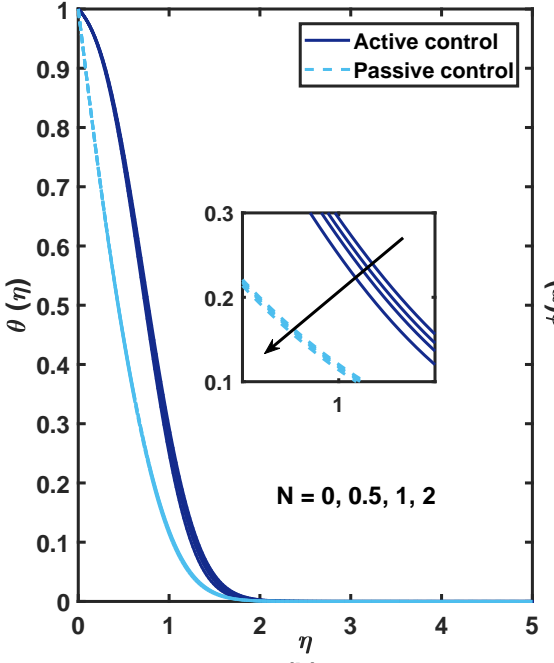

(b)

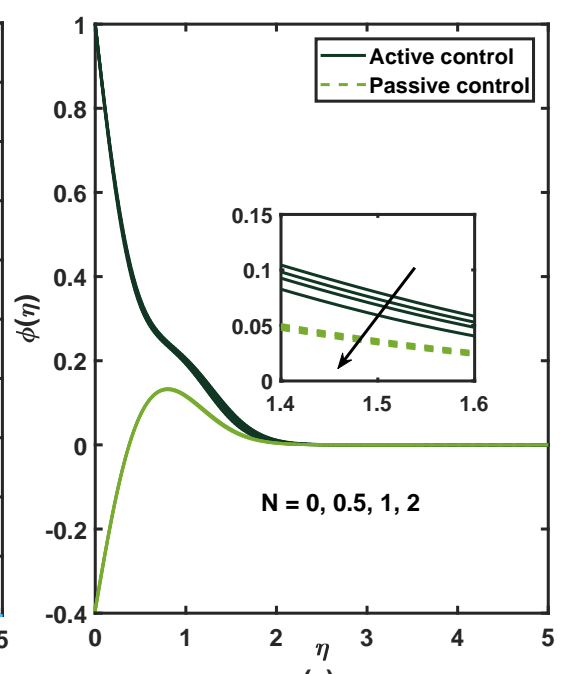

(c)

Figure 6. Impact of buoyancy ratio parameter $N$ on (a) velocity, (b) temperature, and (c) nanoparticle volume fraction profiles.

The effects of nanoparticles can be seen through thermophoresis parameter $N t$ and Brownian motion parameter $\mathrm{Nb}$ in Figures 7 and 8 . The parameter $N t$ has increasing effects towards all three fluid profiles. Thermophoresis represents the movement of particles due to the temperature gradient. Increasing values of $N t$ mean increasing movement due to increasing temperature gradient. Concentration will also increase following the movement of the particles. On the other hand, Brownian motion represents the motion of particles due to their collision with each other. Increasing values of $\mathrm{Nb}$ will cause the fluid velocity and concentration to decrease, but as the collision produces heat, the fluid temperature will increase. However, note that temperature under passive control remains constant and is not affected by the changes in $N b$.

$$
r=0.2, \epsilon=0.3, \delta=0.1, \gamma=\operatorname{Le}=1, \mathrm{~N}=\mathrm{Nb}=0.5, \operatorname{Pr}=5
$$

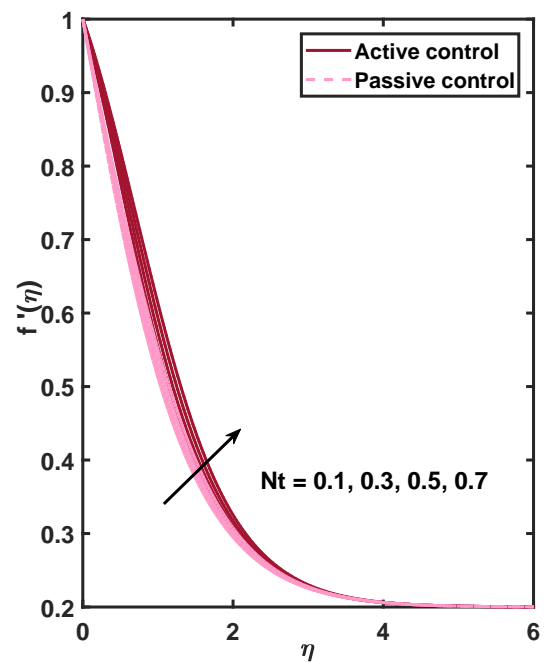

(a)

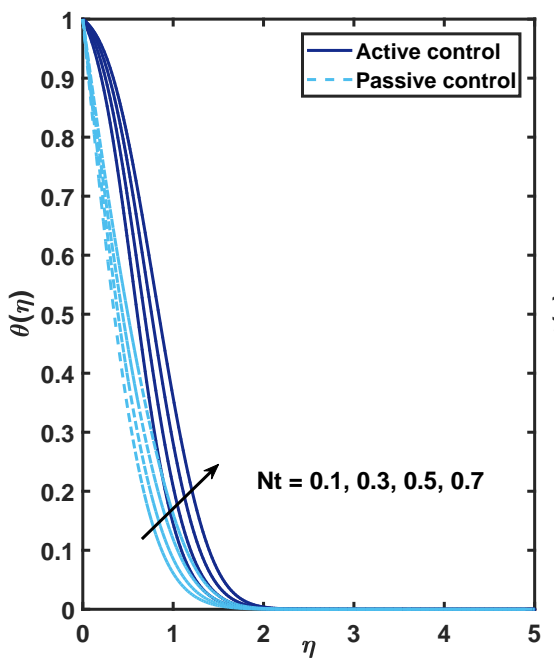

(b)

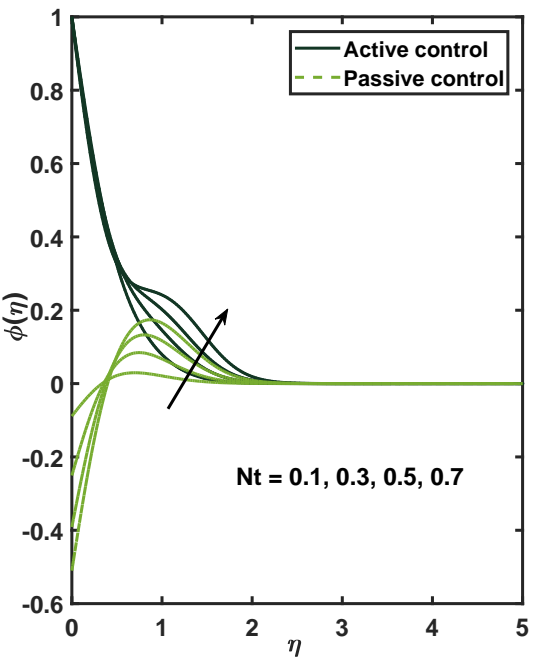

(c)

Figure 7. Impact of thermophoresis parameter $N t$ on (a) velocity, (b) temperature, and (c) nanoparticle volume fraction profiles. 


$$
\mathrm{r}=0.2, \epsilon=0.3, \delta=0.1, \gamma=\mathrm{Le}=1, \mathrm{~N}=\mathrm{Nt}=0.5, \operatorname{Pr}=5
$$

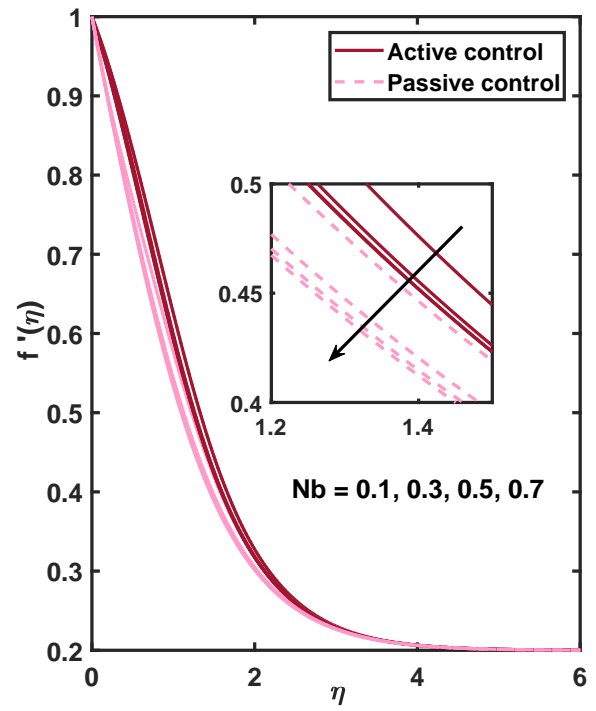

(a)

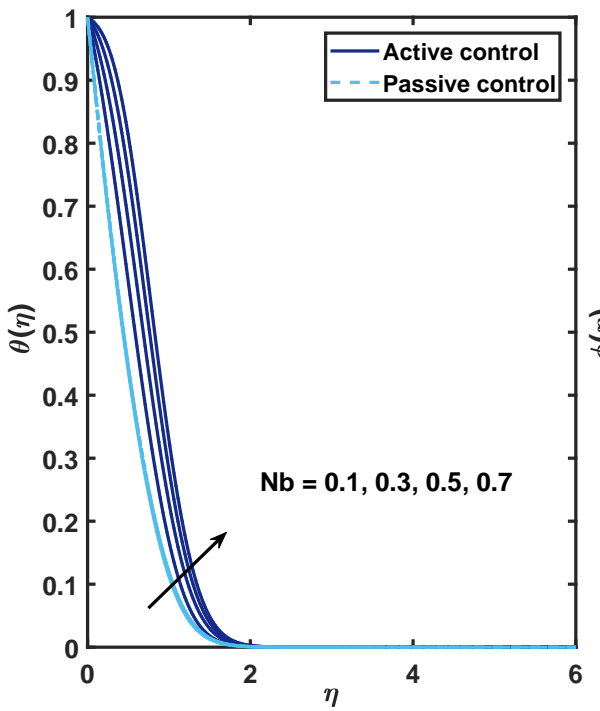

(b)

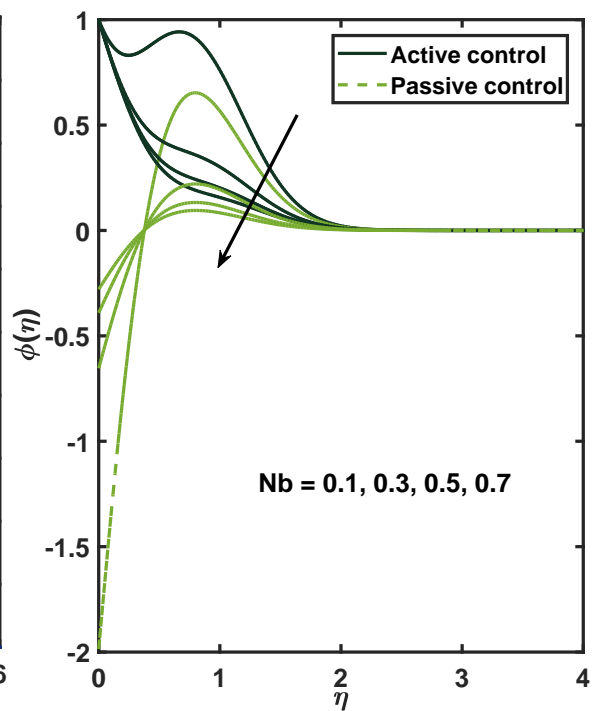

(c)

Figure 8. Impact of Brownian motion parameter $\mathrm{Nb}$ on (a) velocity, (b) temperature, and (c) nanoparticle volume fraction profiles.

Last but not least are the influences of Lewis numbers Le and $\mathrm{Pr}$ towards the fluid profiles as shown in Figures 9 and 10, respectively. Interesting results can be seen in the temperature profile between active and passive controls when $L e$ is varied, where the trends turn out to be opposite to each other. Increasing Le will cause the temperature to rise under passive control but to decline under active control. Other than that, the fluid has a decreasing trend when $L e$ and $P r$ increase.

$$
\mathrm{r}=0.2, \epsilon=0.3, \delta=0.1, \gamma=1, \mathrm{~N}=\mathrm{Nb}=\mathrm{Nt}=0.5, \mathrm{Pr}=5
$$

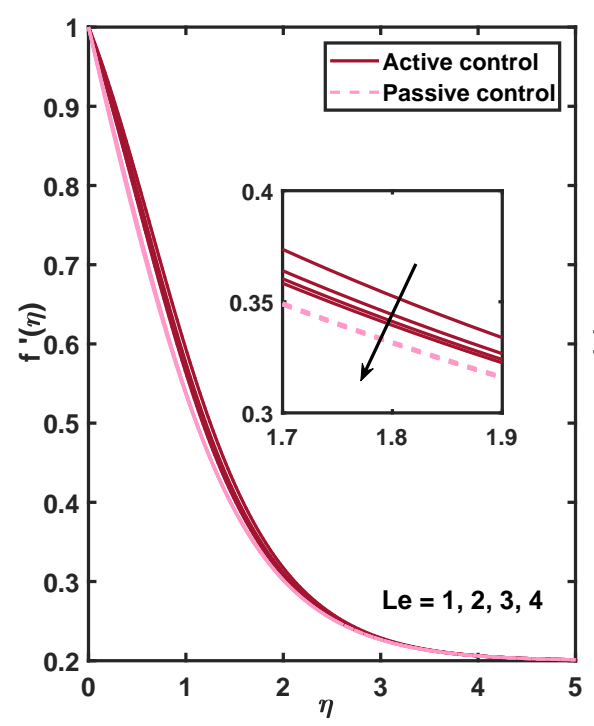

(a)

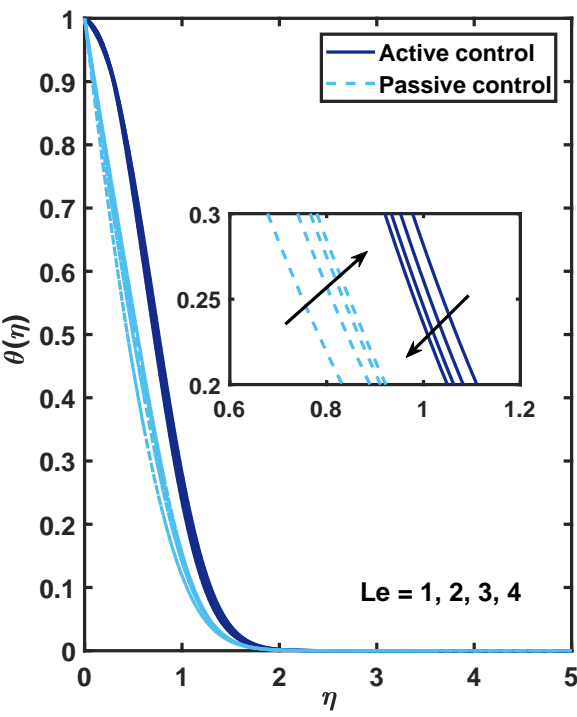

(b)

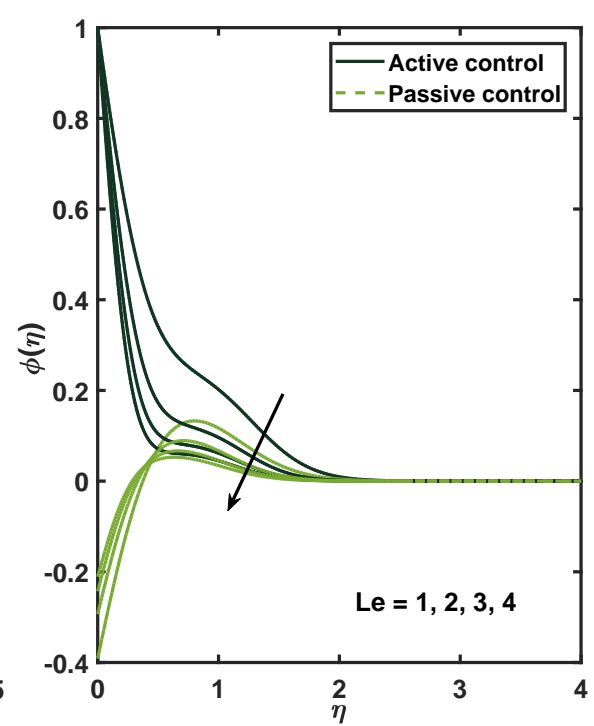

(c)

Figure 9. Impact of Lewis number Le on (a) velocity, (b) temperature, and (c) nanoparticle volume fraction profiles. 
$\mathrm{r}=0.2, \epsilon=0.3, \delta=0.1, \gamma=\mathrm{Le}=1, \mathrm{~N}=\mathrm{Nb}=\mathrm{Nt}=0.5$

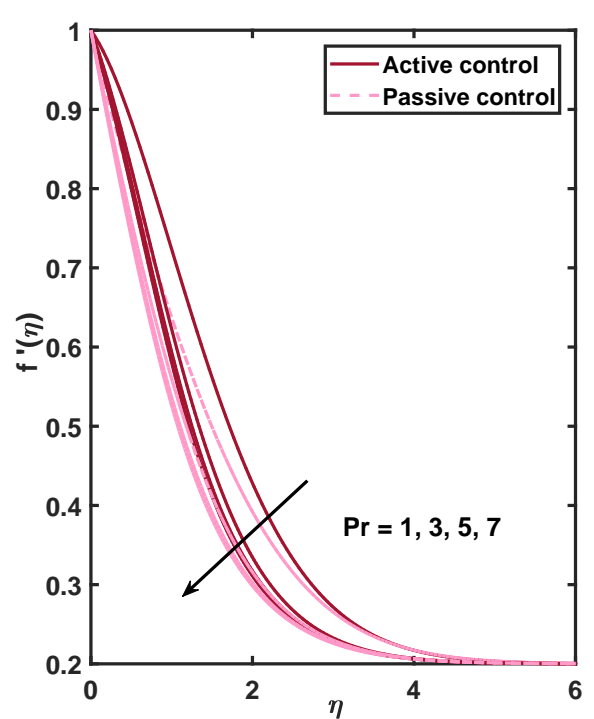

(a)

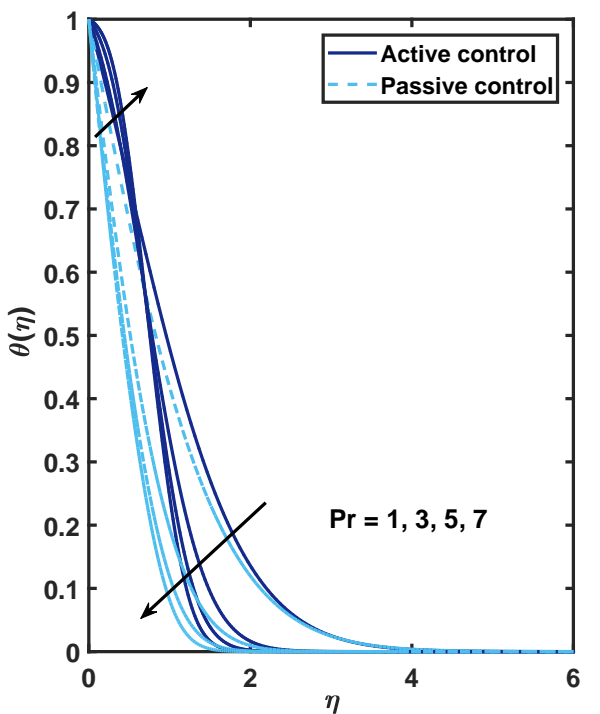

(b)

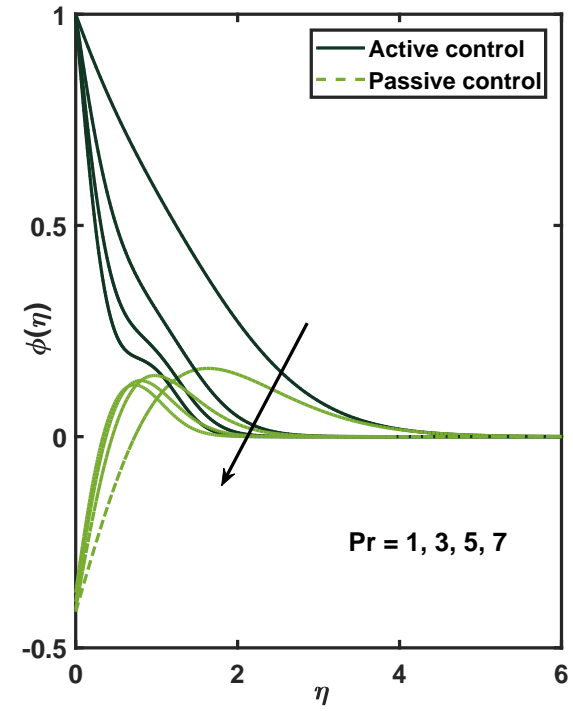

(c)

Figure 10. Impact of Prandtl number $\operatorname{Pr}$ on (a) velocity, (b) temperature, and (c) nanoparticle volume fraction profiles.

\subsection{Skin Friction Coefficient, Nusselt Number, and Sherwood Number}

Tables 2 and 3 list the values of $f^{\prime \prime}(0),-\theta^{\prime}(0)$, and $-\phi^{\prime}(0)$ under both active and passive controls. Magnitude of the skin friction coefficient shows similar trends under active control as well as passive control when $\gamma, N t$, and $P r$ are varied. It increases with increasing $\gamma$ in opposing flows but decreases with increasing $\gamma$ in assisting flows. When there is no buoyancy force, the magnitude of $f^{\prime \prime}(0)$ will remain the same between active and passive controls. Other parameters will result in opposite trends of $f^{\prime \prime}(0)$ between active and passive controls. Parameter $r, \gamma, N$, and $\operatorname{Pr}$ will help in enhancing the heat transfer rate of the fluid, while parameters $\mathrm{Nt}, \mathrm{Nb}$, and Le do the opposite. Varying the fluid parameter $\epsilon$ decreases the heat transfer under active control but increases it under passive control. Meanwhile, fluid parameter $\delta$ has a very minimal influence on heat and mass transfer of the fluid, as the magnitude barely changes when $\delta$ increases and heat transfer remains stagnant under active control. Increasing values of parameters $r, \epsilon, \gamma, N, N t$, and $\operatorname{Pr}$ will contribute to improving the mass transfer rate of the fluid. Interestingly, parameter $\mathrm{Nb}$ shows a more dynamic trend under active control for skin friction coefficient and mass transfer rate. The result is highlighted in Figure 11. With small values of $\mathrm{Nb}$, the trend of $f^{\prime \prime}(0)$ seems to be increasing, but at a certain point it starts to decline. On the other hand, $-\phi^{\prime}(0)$ increases until $\mathrm{Nb}$ reaches a large enough number and starts to decrease. 


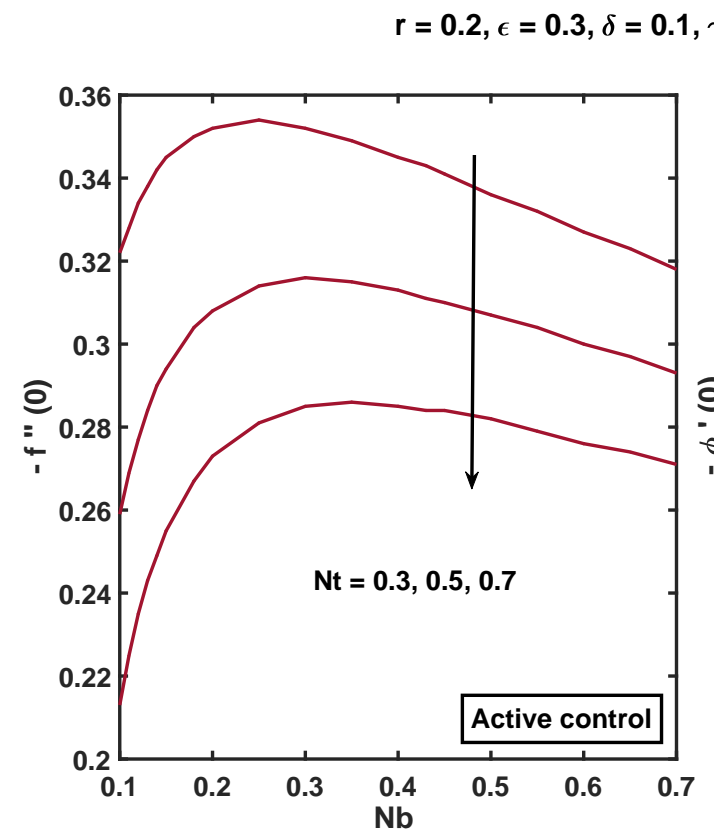

(a)

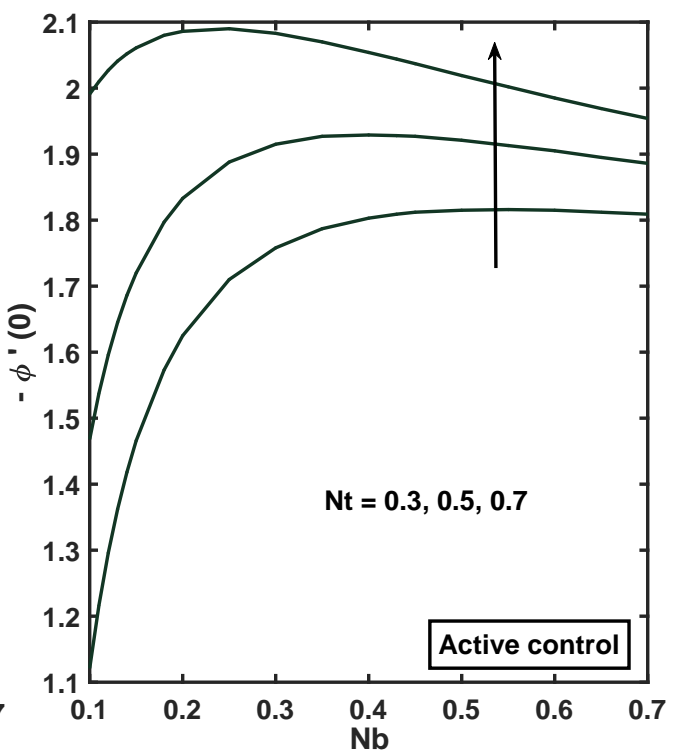

(b)

Figure 11. Impact of Brownian motion parameter $N b$ with varied thermophoresis parameter $N t$ on (a) skin friction coefficient $f^{\prime \prime}(0)$ and (b) mass transfer rate $-\theta(0)$.

\section{Conclusions}

The model of a steady two-dimensional stagnation point flow of a Powell-Eyring nanofluid with mixed convection is examined. The main observations of the study are listed below:

- Stagnation parameter $r$ has a bigger impact on the heat transfer rate under passive control of nanoparticles.

- Both fluid parameters $\epsilon$ and $\delta$ have minimal impacts on the fluid flow.

- Assisting flow has higher rates of heat and mass transfer as compared to the opposing flow.

- Both Brownian parameter, $\mathrm{Nb}$, and thermophoresis parameter, $\mathrm{Nt}$, lower the heat transfer rate of the fluid.

- The heat transfer rate is higher under passive control of nanoparticles than the heat transfer rate in active control of nanoparticles.

Active and passive controls of nanoparticles are practical areas that should not be simply avoided while stagnation points occur everywhere in many applications and instrumental designs. From the observations above, engineers, technologists, and manufacturers who use or are exposed to nanoparticles or nanofluids in their products or processes, especially involving heat exchanger systems, should take note of the importance of controlling the nanoparticles, as they can heavily affect the distribution of heat and mass fluxes that may cause defects to their instruments or final outputs.

Author Contributions: Conceptualization, N.F.M.N.; methodology, N.A.H.; software, N.A.H.; validation, N.A.H. and N.F.M.N.; formal analysis, N.A.H. and N.F.M.N.; investigation, N.A.H. and N.F.M.N.; resources, N.A.H. and N.F.M.N.; data curation, N.A.H.; writing-original draft preparation, N.A.H.; writing-review and editing, N.A.H. and N.F.M.N.; visualization, N.A.H.; supervision, N.F.M.N.; project administration, N.F.M.N.; funding acquisition, N.F.M.N. All authors have read and agreed to the published version of the manuscript.

Funding: This research is funded by the Ministry of Higher Education, Malaysia, under the research grant FRGS/1/2020/STG06/UM/02/1 (FP009-2020). 
Acknowledgments: We thank the respected anonymous reviewer/s who contributed towards the improvement of this paper.

Conflicts of Interest: The authors declare no conflict of interest.

\section{Nomenclature}

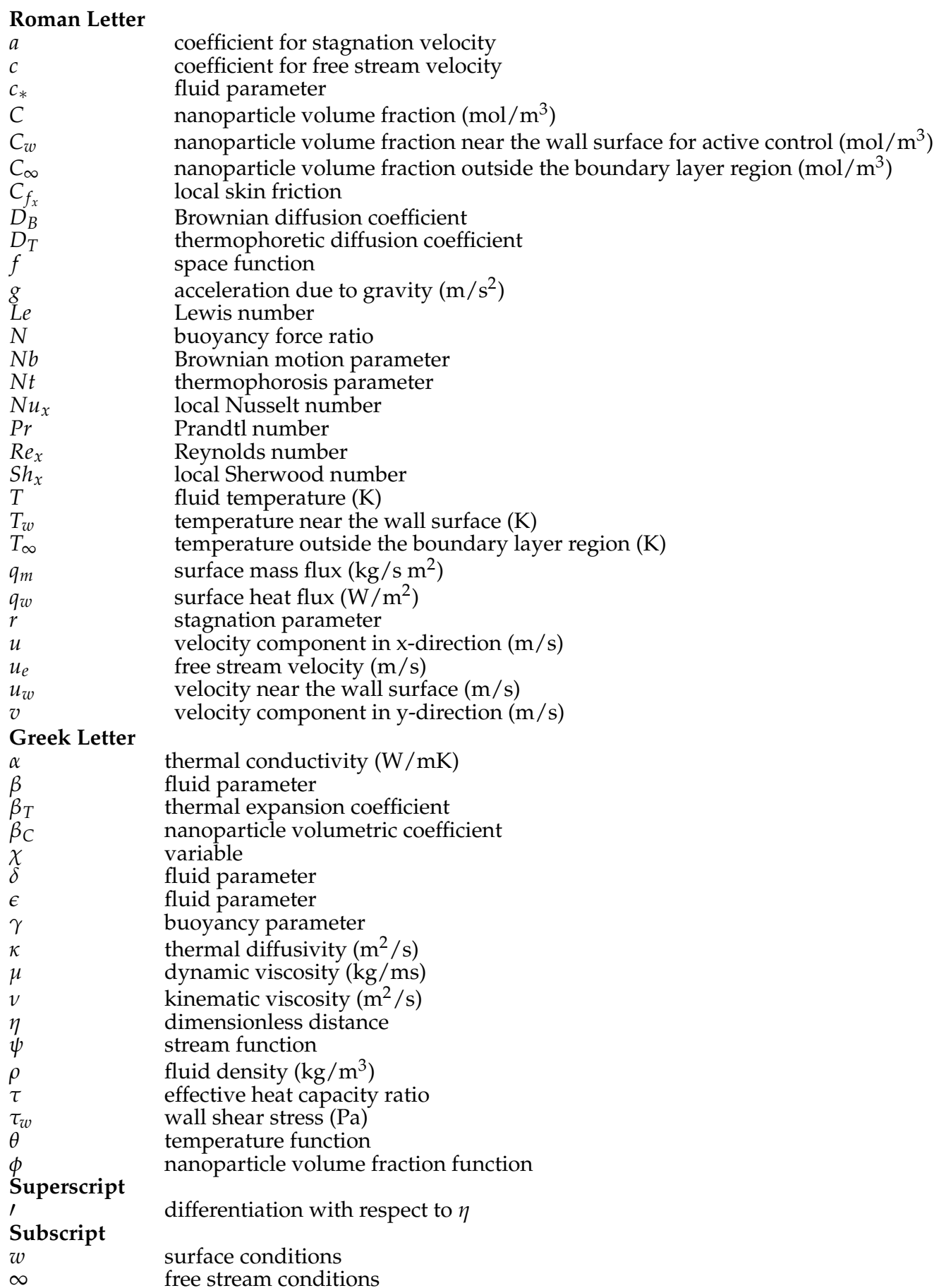




\section{References}

1. Chen, T.S.; Sparrow, E.M.; Mucoglu, A. Mixed convection in boundary layer flow on a horizontal plate. J. Heat Transf. 1977, 99, 66-71. [CrossRef]

2. Ramachandran, N.; Chen, T.S.; Armaly, B.F. Mixed convection in stagnation flows adjacent to vertical surfaces. J. Heat Transf. 1988, 110, 373-377. [CrossRef]

3. Merkin, J.H. On dual solutions occurring in mixed convection in a porous medium. J. Eng. Math. 1986, 20, 171-179. [CrossRef]

4. Ishak, A.; Nazar, R.; Amin, N.; Filip, D.; Pop, I. Mixed convection of the stagnation-point flow towards a stretching vertical permeable sheet. Malays. J. Math. Sci. 2007, 1, 217-226.

5. Ishak, A.; Nazar, R.; Bachok, N.; Pop, I. MHD mixed convection flow near the stagnation-point on a vertical permeable surface. Phys. A Stat. Mech. Its Appl. 2010, 389, 40-46. [CrossRef]

6. Bognar, G. On similarity solutions of boundary layer problems with upstream moving wall in non-Newtonian power-law fluids. IMA J. Appl. Math. 2011, 77, 546-562. [CrossRef]

7. Hayat, T.; Abbas, Z.; Pop, I.; Asghar, S. Effects of radiation and magnetic field on the mixed convection stagnation-point flow over a vertical stretching sheet in a porous medium. Int. J. Heat Mass Transf. 2010, 53, 466-474. [CrossRef]

8. Aman, F.; Ishak, A.; Pop, I. Mixed convection boundary layer flow near stagnation-point on vertical surface with slip. Appl. Math. Mech. 2011, 32, 1599-1606. [CrossRef]

9. Abbas, Z.; Wang, Y.; Hayat, T.; Oberlack, M. Mixed convection in the stagnation-point flow of a Maxwell fluid towards a vertical stretching surface. Nonlinear Anal. Real World Appl. 2010, 11, 3218-3228. [CrossRef]

10. Hayat, T.; Shehzad, S.A.; Alsaedi, A.; Alhothuali, M.S. Mixed convection stagnation point flow of Casson fluid with convective boundary conditions. Chin. Phys. Lett. 2012, 29, 114704. [CrossRef]

11. Tian, X.Y.; Li, B.W.; Hu, Z.M. Convective stagnation point flow of a MHD non-Newtonian nanofluid towards a stretching plate. Int. J. Heat Mass Transf. 2018, 127, 768-780. [CrossRef]

12. Choi, S.U.S.; Eastman, J.A. Enhancing thermal conductivity of fluids with nanoparticles. ASME Publ. Fed 1995, 231, 99-106.

13. Makinde, O.D.; Khan, W.A.; Khan, Z.H. Buoyancy effects on MHD stagnation point flow and heat transfer of a nanofluid past a convectively heated stretching/shrinking sheet. Int. J. Heat Mass Transf. 2013, 62, 526-533. [CrossRef]

14. Pal, D.; Mandal, G. Mixed convection-radiation on stagnation-point flow of nanofluids over a stretching/shrinking sheet in a porous medium with heat generation and viscous dissipation. J. Pet. Sci. Eng. 2015, 126, 16-25. [CrossRef]

15. Hsiao, K.L. Stagnation electrical MHD nanofluid mixed convection with slip boundary on a stretching sheet. Appl. Therm. Eng. 2016, 98, 850-861. [CrossRef]

16. Abbasi, F.M.; Shehzad, S.A.; Hayat, T.; Alhuthali, M.S. Mixed convection flow of Jeffrey nanofluid with thermal radiation and double stratification. J. Hydrodyn. Ser. B 2016, 28, 840-849. [CrossRef]

17. Othman, N.A.; Yacob, N.A.; Bachok, N.; Ishak, A.; Pop, I. Mixed convection boundary-layer stagnation point flow past a vertical stretching/shrinking surface in a nanofluid. Appl. Therm. Eng. 2017, 115, 1412-1417. [CrossRef]

18. Zaib, A.; Khan, U.; Khan, I.; Seikh, A.H.H.; Sherif, E.S.M.M. Entropy Generation and Dual Solutions in Mixed Convection Stagnation Point Flow of Micropolar Ti6Al4V Nanoparticle along a Riga Surface. Processes 2019, 8, 14. [CrossRef]

19. Alizadeh, R.; Karimi, N.; Nourbakhsh, A. Effects of radiation and magnetic field on mixed convection stagnation-point flow over a cylinder in a porous medium under local thermal non-equilibrium. J. Therm. Anal. Calorim. 2019, 140, 1371-1391. [CrossRef]

20. Jamaludin, A.; Nazar, R.; Pop, I. Mixed convection stagnation-point flow of a nanofluid past a permeable stretching/shrinking sheet in the presence of thermal radiation and heat source/sink. Energies 2019, 12, 788. [CrossRef]

21. Khan, M.; Salahuddin, T.; Tanveer, A.; Malik, M.Y.; Hussain, A. Change in internal energy of thermal diffusion stagnation point Maxwell nanofluid flow along with solar radiation and thermal conductivity. Chin. J. Chem. Eng. 2019, 27, 2352-2358. [CrossRef]

22. Hayat, T.; Sajjad, R.; Muhammad, T.; Alsaedi, A.; Ellahi, R. On MHD nonlinear stretching flow of Powell-Eyring nanomaterial. Results Phys. 2017, 7, 535-543.

23. Hussain, Q.; Alvi, N.; Latif, T.; Asghar, S. Radiative heat transfer in Eyring-Powell nanofluid with peristalsis. Int. J. Thermophys. 2019, 40, 46. [CrossRef]

24. Ibrahim, W.; Gadisa, G. Finite Element Method Solution of Boundary Layer Flow of Eyring-Powell Nanofluid over a Nonlinear Stretching Surface. J. Appl. Math. 2019, 2019, 3472518.

25. Ogunseye, H.A.; Mondal, H.; Sibanda, P.; Mambili-Mamboundou, H. Lie group analysis of a Powell-Eyring nanofluid flow over a stretching surface with variable properties. SN Appl. Sci. 2019, 2. [CrossRef]

26. Khan, I.; Fatima, S.; Malik, M.Y.; Salahuddin, T. Exponentially varying viscosity of magnetohydrodynamic mixed convection Eyring-Powell nanofluid flow over an inclined surface. Results Phys. 2018, 8, 1194-1203.

27. Ogunseye, H.A.; Sibanda, P. A mathematical model for entropy generation in a Powell-Eyring nanofluid flow in a porous channel. Heliyon 2019, 5, e01662. [CrossRef] [PubMed]

28. Alsaedi, A.; Hayat, T.; Qayyum, S.; Yaqoob, R. Eyring-Powell nanofluid flow with nonlinear mixed convection: Entropy generation minimization. Comput. Methods Programs Biomed. 2020, 186, 105183. [CrossRef] [PubMed]

29. Waqas, M.; Jabeen, S.; Hayat, T.; Shehzad, S.A.; Alsaedi, A. Numerical simulation for nonlinear radiated Eyring-Powell nanofluid considering magnetic dipole and activation energy. Int. Commun. Heat Mass Transf. 2020, 112, 104401. [CrossRef]

30. Aziz, A.; Jamshed, W.; Aziz, T.; Bahaidarah, H.M.S.; Rehman, K.U. Entropy analysis of Powell-Eyring hybrid nanofluid including effect of linear thermal radiation and viscous dissipation. J. Therm. Anal. Calorim. 2020. [CrossRef] 
31. Hayat, T.; Farooq, M.; Alsaedi, A.; Iqbal, Z. Melting heat transfer in the stagnation point flow of Powell-Eyring fluid. J. Thermophys. Heat Transf. 2013, 27, 761-766. [CrossRef]

32. Buongiorno, J. Convective transport in nanofluids. J. Heat Transf. 2006, 128, 240-250. [CrossRef]

33. Ishfaq, N.; Khan, Z.H.; Khan, W.A.; Culham, R.J. Estimation of boundary-layer flow of a nanofluid past a stretching sheet: A revised model. J. Hydrodyn. 2016, 28, 596-602. [CrossRef] 